Open Access

\title{
The effects of computer-based virtual learning environments on nursing students' mathematical learning in medication processes
}

\author{
Diana P. Zwart ${ }^{1 *}$ (D), Sui Lin Goei ${ }^{1,2}$, Omid Noroozi ${ }^{3}$ and Johannes E. H. Van Luit ${ }^{4}$
}

\author{
*Correspondence: dp.zwart@ \\ windesheim.nl \\ 'Department of Human Movement \\ and Education, Windesheim \\ University of Applied Sciences, \\ Campus 2-6, 8000, GB, Zwolle, the \\ Netherlands \\ Full list of author information is \\ available at the end of the article
}

\begin{abstract}
Computer-based virtual learning environments (CBVLEs) are potentially useful teaching tools for training nursing students in professional duties such as the mathematical tasks associated with medication processes. In this study, a CBVLE was designed with well-structured instructional activities such as interleaved practice and feedback. Mathematical medication scenarios and basic arithmetic exercises were integrated into the CBVLE. Four training conditions were used in the CBVLE to facilitate extra support for mathematical medication learning: (1) learning without worked examples, (2) learning with worked examples involving domain-specific knowledge, (3) learning with worked examples involving regular thinking strategies, and (4) learning with combined worked examples. This study was conducted with 118 nursing students enrolled in post-secondary nursing education and Bachelor's nursing programmes. Students were pre-tested and post-tested on their mathematical medication learning. Training in the CBVLE improved mathematical medication learning for all students from pre-test to the post-test stages, but no differences were found among the four different conditions. Nursing students' prior knowledge, non-verbal intelligence, and number of correct tasks predicted mathematical medication learning outcomes. When controlling for non-verbal intelligence, students in the condition 1 benefited more than students in condition 3 in terms of their mathematical medication learning outcomes. The same accounted for the support of the low-achieving students in the CBVLE. The support conditions for the high-achieving group appeared to be unimportant for mathematical medication learning. It seems that technology is taken over some of the capacity of working memory, which accounts for the benefits to the low-achieving learners.
\end{abstract}

Keywords: Virtual learning, Instructional design, Mathematics, Medication, Nursing 


\section{Introduction}

Nursing students are trained in mathematical medication skills for future high-risk professional care situations in which they will need to check, prepare, distribute, administer, and evaluate medication for patients. These are important skills, and even a simple mistake could create serious complications for the patient (Prins, Zwart, Voogt, \& Hettinga, 2019). The medication process is complex and involves the application of theoretical knowledge of medicines, administration of medications, communication, hygiene, and calculation of dosages. The latter requires a conceptual understanding, since it involves knowledge about the underlying unifying principles (Canobi, 2009). To train for this complexity and the challenges of conceptual understanding, nursing students' skills in terms of these high-risk professional practices can be trained using a lifelike computer-based virtual learning environment (CBVLE). This is a simulated environment specifically designed to contain a variety of mathematical medication scenarios and basic computational arithmetic exercises that visualise the underlying unifying mathematical principles that students need to apply when solving complex mathematical medication tasks (Wang, Kirschner, Spector, \& Ge, 2018).

In a CBVLE, numerous different kinds of mathematical medication problems can be offered, so that students can train for interleaved practice (Dunlosky, Rawson, Marsh, Nathan, \& Willingham, 2013; Rohrer, Dedrick, \& Burgress, 2014; Rohrer, Dedrick, \& Stershic, 2015). In interleaved practice, students are trained on different types of problems over time. This requires students to make connections between the various problems, and thus provides a broader knowledge base that allows them to grasp the procedure for solving different domain-specific types of maths problems. When students make mistakes while solving problems, feedback is provided by giving the correct answer accompanied by domain-specific mathematical rules (Dunlosky et al., 2013; Hattie \& Timperly, 2007). This should, however, be combined with feedback at the process level, so that students also pay close attention to adequate strategies and domain-specific rules for an appropriate conception of the task (Hattie \& Timperly, 2007; Nicol \& Macfarlane-Dick, 2006).

Although the instructional activities of interleaved practice and feedback are relevant, they may not facilitate learning via a CBVLE for all students. Support for cognitive approaches plays an important role in helping students persist and to overcome challenges and setbacks (Wang et al., 2018). One way of providing students with cognitive approaches is the use of worked examples (Kirschner, Sweller, Kirschner, \& Zambrano, 2018; Sweller, 2010; Van Gog, Kester, \& Paas, 2011). These are effective instructional procedures that can be embedded in the CBVLE to show students how to solve specific mathematical problems (Chen, Kalyuaga, \& Sweller, 2016; Kirschner et al., 2018; Van Gog et al., 2011). Worked examples can be combined in various ways, such as elaborate mathematical medication examples that illustrate how to apply procedures to specific cases (Chen et al., 2016; Kirschner et al., 2018; Van Gog et al., 2011), or can be combined with regular problem-solving steps to emphasise thinking strategies that increase transfer to other problem issues (Ben-David \& Zohar, 2009; Hattie \& Timperly, 2007). Though worked examples can enhance the acquisition of domain-specific and domaingeneral knowledge, their use may lead to overloading of students' working memory (Kirschner et al., 2018). The main purpose of this study is to investigate how training in a CBVLE with or without worked examples can facilitate mathematical medication learning by nursing students. 


\section{Theoretical framework}

\section{Computer-based virtual learning environments}

CBVLEs are simulated environments that can be programmed with scenarios involving professional learning tasks, with a focus on making tacit aspects of learning tasks and related knowledge visible and accessible to students (Wang et al., 2018). CBVLEs enable students to interact with their future professional world and allow them to be trained on and understand complex tasks. Using CBVLEs, students can interact with their peers via a keyboard, mouse, joystick, or touch screen (Lee \& Wong, 2014; Lee, Wong, \& Fung, 2010; Noroozi, Biemans, Weinberger, Mulder, \& Chizari, 2013), and during this process, they are immersed in computer-based environments (Shute, Ventura, Bauer, \& Zapata-Rivera, 2009).

The design of a CBVLE includes features such as interactive stories and requires practical and clear objectives to ensure that students have immersive experiences in a virtual world and to create a 'state of flow' in which students can succeed only through effort (Csikszentmihalyi, 1990; Shute et al., 2009). A CBVLE can illuminate learning experiences and make situations more authentic by including learning tasks with essential aspects that students need to master for their future profession. A CBVLE makes it possible to concretise abstract ideas and concepts by reorganising integrated facts, procedures, and ideas so that they are retrievable and easy to practice (Pollock, Chandler, \& Sweller, 2002; Xinhao \& Fengfeng, 2016).

When various scenarios, involving students' professional learning tasks are embedded, CBVLEs offer potential situated learning possibilities, allowing students to train for future professional knowledge and skills. Nevertheless, as in traditional classroom settings, the instructional activities within CBVLEs such as interleaved practice and feedback need to be considered.

\section{Instructional activities in a CBVLE}

\section{Interleaved practice}

Interleaved practice refers to practising different types of problems over time (Dunlosky, 2013). Interleaved mathematics distribute problems of the same kind, across different assignments (Rohrer et al., 2014). It is a learning technique that allows students to study conceptual and technical features and the relationships between them and has a positive effect on future retention (Roediger \& Karpicke, 2006; Weeks et al., 2013). 'Students practice several instances of one type of math problem (e.g., addition) before practicing the next type (e.g., subtraction). Interleaving would involve one mathematical problem from each type before solving a new mathematical problem from each type' (Dunlosky, 2013, p. 16). Interleaved practice provides students with a broader knowledge base (Dunlosky et al., 2013; Rohrer et al., 2015). According to Rohrer et al. (2014), interleaved practice has two important characteristics: Firstly, problems of different kinds are interleaved that allow students to learn a strategy. Secondly, problems of the same kind are distributed that enhance students' retention. Practising many different domain-specific types of mathematical problems permits the student to grasp the procedures and to make connections between various subjects. This improves students' achievements in the domain of mathematical problem-solving (Dunlosky, 2013). To make the learning process in a CBVLE explicit, the structure of the learning 
environment can be programmed with feedback at the task and process levels (Hattie \& Timperly, 2007; Nicol \& Macfarlane-Dick, 2006).

\section{Feedback}

Feedback is defined as the information provided by a teacher, peer or computer on a student's performance or understanding to promote learning (Hattie \& Gan, 2011; Hattie \& Timperly, 2007). Feedback should be informative and include corrective advice that can help students move towards their learning goals (Dunlosky et al., 2013; Nicol \& Macfarlane-Dick, 2006). (Sadler (2010), p. 536) states that 'feedback on complex learning may incorporate a variety of elements', and these include a description of the global quality of the work; praise, encouragement, or other affective comments; and suggestions on how to attend to specific deficiencies and strengthen the work as a whole. This should be combined with feedback at the process level, since right strategies and domain-specific rules are key issues that deserve students' special attention for an appropriate understanding of the task (Hattie \& Timperly, 2007; Nicol \& Macfarlane-Dick, 2006). Feedback at the process level, as a reflection on learning, can be given after each round of play (Nicol \& Macfarlane-Dick, 2006). Reflection on learning is necessary for students to become aware of their own thinking processes (Schön, 1983), as it closes the gap between what students learn and what they know. However, interleaved practice and feedback in a CBVLE may not facilitate learning for all students. Support for cognitive approaches plays an important role in helping students persist in the face of challenges and setbacks (Wang et al., 2018). One method of providing students with cognitive approaches and place emphasis on appropriate cognitive rules is the use of worked examples (Kirschner et al., 2018; Sweller, 2010; Van Gog et al., 2011).

\section{Worked examples}

Worked examples are effective instructional procedures (Kirschner et al., 2018; Sweller, 2010; Van Gog et al., 2011) that can support students in solving problems and help in connecting prior knowledge to new knowledge (Ausubel, 1968; Tynjälä, 2013). They may take the form of domain-specific scaffolds for problem-solving (Sweller, 2010). Whereas an unguided problem does not indicate which elements should be attended to, a worked example does; this reduces the number of elements that must be processed in working memory (Chen et al., 2016;Eiriksdottir \& Catrambone, 2011 ; Margulieux \& Catrambone, 2016). Worked examples can support low-achieving students to acquire the domain-specific knowledge (Kalyuga, Chandler, \& Sweller, 2001a; Kalyuga, Chandler, Tuovinen, \& Sweller, 2001b; Tricot \& Sweller, 2014; Van Gog et al., 2011). However, they can also have adverse effects: once levels of expertise have increased, they become redundant, particularly for high-achieving students.

Worked examples promote conceptual understanding and transfer and demonstrate how to apply procedures to specific cases (Eiriksdottir \& Catrambone, 2011; Margulieux \& Catrambone, 2016). This also represents a drawback of worked examples, since they are bound to a specific context (Margulieux \& Catrambone, 2016). Worked examples can also be combined with problem-solving steps to emphasise regular thinking strategies, and this approach can increase transfer to other learning situations (Ben- 
David \& Zohar, 2009). These regular thinking strategies provoke students' active thinking and foster deep learning (Zohar \& David, 2008). Thus, the use of worked examples can serve to support both regular thinking strategies and the organisation of the mathematical domain-specific knowledge needed to solve complex mathematical medication problems.

\section{Mathematical medication and domain-specific knowledge}

Mathematical medication requires not only a theoretical knowledge of medicines and their administration, but also a mathematical domain-specific knowledge of medication (Prins et al., 2019). Mathematical medication demands basic computational skills such as addition, subtraction, multiplication, and division of whole numbers, units of measurement, decimals, fractions, and conversion between them (Weeks et al, 2013). This knowledge is often invisible; it is the underlying unifying knowledge that is featured in mathematical medication problems. Canobi (2009) describes these principles as the structure underlying the problem domain of mathematical medication, which calls for a conceptual understanding by students. It includes both an implicit and an explicit understanding of the principles that govern a domain and of the interrelations between units of knowledge in a domain (Krathwohl, 2002; Rittle-Johnson, Siegler, \& Alibali, 2001).

Although conceptual knowledge is flexible, and is not tied to specific problem types, competence in a particular domain requires not only a knowledge of concepts, but also procedural knowledge (Rittle-Johnson et al., 2001). Procedural knowledge is tied to specific problem types and involves the ability to execute action sequences to solve mathematical problems (Krathwohl, 2002). It requires domain-specific knowledge, since this is the best predictor of the performance of a task (Tricot \& Sweller, 2014). The acquisition of domain-specific knowledge also plays an important role when solving problems (Polya, 1973; Tricot \& Sweller, 2014). Ben-David and Zohar (2009) find that an emphasis on thinking strategies can increase transfer to other issues, while Rittle-Johnson et al. (2001) emphasise the importance of examining both conceptual and procedural knowledge together; however, according to Kirschner, Sweller, and Clark (2006) and Wang et al. (2018), presenting domain-specific knowledge with the relevant underlying domain-specific principles makes it easier to retrieve and apply the knowledge needed to solve problems.

Table 1 shows domain-specific mathematical knowledge from the field of mathematical medication, which is categorised in this study into the three domains of liquid medication, infusion fluids, and solid medication. Procedural knowledge tied to these specific areas and the domain-specific principles underlying mathematical medication are mentioned in columns 3 and 4 of the table, respectively, while the last two columns give examples of mathematical medication scenarios across domains and examples of exercises for practising the underlying domain-specific principles in the CBVLE.

\section{Programming instructional activities and simulations in the CBVLE}

Simulations can support learning by providing virtual activities and procedures that reflect or replicate those required in the real world, frequently using visually compelling environments (Boyle et al., 2016). In our CBVLE, interleaving practice involves learning 
Table 1 Aspects of domain-specific mathematical knowledge related to 'liquid medication', 'infusion fluid', and 'solid medication' in a CBVLE

\begin{tabular}{|c|c|c|c|c|c|}
\hline $\begin{array}{l}\text { Medication } \\
\text { domains }\end{array}$ & $\begin{array}{l}\text { Domain- } \\
\text { specific } \\
\text { knowledge }\end{array}$ & $\begin{array}{l}\text { Procedures } \\
\text { (domain-specific } \\
\text { rules for } \\
\text { feedback and } \\
\text { worked } \\
\text { examples) }\end{array}$ & $\begin{array}{l}\text { Underlying } \\
\text { domain- } \\
\text { specific } \\
\text { principles } \\
\text { for all } \\
\text { domains }\end{array}$ & $\begin{array}{l}\text { Learning tasks } \\
\text { (examples of } \\
\text { mathematical } \\
\text { medication scenarios in } \\
\text { a CBVLE) }\end{array}$ & $\begin{array}{l}\text { Underlying } \\
\text { principles } \\
\text { (examples of } \\
\text { exercises for } \\
\text { computational } \\
\text { abilities in a } \\
\text { CBVLE) }\end{array}$ \\
\hline $\begin{array}{l}\text { Liquid } \\
\text { medication } \\
\text { (incl. } \\
\text { dilution) }\end{array}$ & $\begin{array}{l}\text { Ratio of the } \\
\text { dissolved } \\
\text { substance } \\
\text { and diluent }\end{array}$ & $\begin{array}{l}\text { Mass/volume } \\
(\mathbf{m} / \mathbf{v}) \\
1 \%=1 \text { gram } \\
\text { dissolved } \\
\text { substance/100 } \mathrm{ml} \\
1 \%=1 \mathrm{gram} \\
\text { dissolved } \\
\text { substance/1000 } \\
\mathrm{ml}(1 \text { litre) } \\
\text { Volume/volume } \\
\text { (v/v) } \\
1 \%=1 \mathrm{ml} \text { liquid/ } \\
100 \mathrm{ml} \\
1 \%=1 \mathrm{ml} \\
\text { liquid/1000 } \mathrm{ml}(1 \\
\text { litre) }\end{array}$ & $\begin{array}{l}\text { Quantities } \\
\text { Units } \\
\text { Conversions } \\
\text { of ratios: } \\
\text { a. Fractions } \\
\text { b. Decimals } \\
\text { c. Numbers } \\
\text { d. } \\
\text { Percentage } \\
\text { Elations } \\
\text { between a, } \\
\text { b, c, and d } \\
\text { Divide } \\
\text { Multiplication } \\
\text { h, min, s } \\
\text { (time ratio) } \\
\text { Elements of } \\
\text { the } \\
\text { prescription } \\
\text { dispensed } \\
\text { Extract } \\
\text { numerical } \\
\text { information } \\
\text { Apply } \\
\text { calculations } \\
\text { correctly and } \\
\text { accurately }\end{array}$ & $\begin{array}{l}\text { P. suffers severe pain. He } \\
\text { is prescribed } 15 \mathrm{mg} \\
\text { morphine every } 4 \text { hours. } \\
\text { Stocked: } 1 \mathrm{ml} \text { morphine } \\
\text { ampoules of } 15 \mathrm{mg} / \mathrm{ml} \text {. } \\
\text { How many } \mathrm{ml} \text { do you } \\
\text { inject every four hours? } \\
\text { How many } \mathrm{ml} \text { is this per } \\
\text { day? }\end{array}$ & $\begin{array}{l}16 \times 8= \\
12 \times 9= \\
1 / 4+3 / 4=1 / 4= \\
3 / 3+5 / 3= \\
3 / 4-2 / 8= \\
14 / 5-9 / 5= \\
3 / 4 \times 4 / 5= \\
5 / 10 \times 4 / 8= \\
4 / 5: 2 / 5= \\
3 / 5: 1 / 3= \\
1 / 4=0.25 \\
1 / 20=0.05 \\
0.09=\ldots \% \\
0.50=\ldots \% \\
75 \%=0.75 \\
30 \%=0.30 \\
\text { How much is: } \\
5 \% \text { of } 1000 \mathrm{ml} ? \\
4 \% \text { of } 250 \mathrm{ml} ? \\
1 \mathrm{~L}=\ldots \mathrm{ML} \\
1 \mathrm{ML}=\ldots \mathrm{CC}\end{array}$ \\
\hline $\begin{array}{l}\text { Infusion } \\
\text { fluid }\end{array}$ & Drip rating & $\begin{array}{l}20 \text { drops/ml } \\
\text { 1. Calculate the } \\
\text { total number of } \\
\text { drips } \\
\text { 2. Calculate the } \\
\text { drips/h } \\
\text { 1. 3. Calculate the } \\
\text { drips/min }\end{array}$ & & $\begin{array}{l}\text { G. is administered a drip } \\
\text { of } 500 \mathrm{ml} 0.9 \% \mathrm{NaCl} \text {. in } \\
\text { three hours. How many } \\
\text { drips are administered to } \\
\text { G. per minute? }\end{array}$ & \\
\hline $\begin{array}{l}\text { Solid } \\
\text { medication }\end{array}$ & $\begin{array}{l}\text { Dosage } \\
\text { calculation } \\
\text { for tablets }\end{array}$ & $\begin{array}{l}\text { Count, divide, } \\
\text { multiply, work } \\
\text { with fractions, } \\
\text { reference } \\
\text { measurements: } \\
24 \mathrm{~h} \text { in a day } \\
60 \mathrm{~min} \text { in an } \mathrm{h} \\
50 \%=1 / 2 \\
1 / 4=25 \% \\
\text { etc. }\end{array}$ & & $\begin{array}{l}\text { F. suffers from cystitis. } \\
\text { She receives treatment } \\
\text { with antibiotics for six } \\
\text { days: } 750 \text { mg Amoxicillin } \\
\text { every } 12 \text { hours. Stocked: } \\
\text { Flemoxin with } 375 \mathrm{mg} \\
\text { Amoxicillin per tablet. } \\
\text { How many tablets should } \\
\text { F. swallow during } \\
\text { treatment? }\end{array}$ & \\
\hline
\end{tabular}

tasks that are programmed as mathematical medication scenarios. The underlying domain-specific principles are introduced in the CBVLE in the form of short exercises, which are necessary to develop a high level of automaticity and require students to make connections between the various subjects in order to grasp the procedures for solving different domain-specific types of mathematical medication problems (Dunlosky et al., 2013; Rohrer et al., 2015). In addition, feedback is programmed in the CBVLE as the information from the procedures column that the computer provides on each student's performance after solving a mathematical medication problem (Dunlosky et al., 2013;Hattie \& Timperly, 2007 ; Nicol \& Macfarlane-Dick, 2006). At the end of each 
practice round, which involves solving six mathematical medication problems and two sets of five short exercises involving the underlying domain-specific principles, nursing students are given feedback at the process level to reflect their learning (Hattie \& Timperly, 2007; Nicol \& Macfarlane-Dick, 2006).

It is currently unclear how learning via a CBVLE, involving a structured learning environment based on the instructional design aspects of interleaved practice and feedback, can facilitate mathematical medication learning by nursing students. Furthermore, there has been little empirical research into the assumption that the embedding of worked examples into a CBVLE, in order to support regular thinking strategies or the organisation of mathematical domain-specific knowledge, has a positive effect on the domain-specific mathematical medication knowledge of nursing students. The following research questions were formulated to address these issues:

1. Which predictors affect the mathematical medication learning of nursing students in a CBVLE?

2. To what extent can a CBVLE foster mathematical medication learning by nursing students without worked examples (condition 1), with worked examples involving domain-specific knowledge (condition 2), with worked examples involving regular thinking strategies (condition 3), and with a combination of both types of worked example (condition 4)?

In the first place, we expect that the use of worked examples with domain-specific knowledge (condition 2) will enhance mathematical medication learning to the greatest extent. Secondly, high-achieving students are expected to score more highly in mathematical medication learning under condition 1, since worked examples are detrimental to the acquisition of skills when levels of expertise are sufficiently high (Kalyuga, Chandler, \& Sweller, 2001a; Kalyuga, Chandler, Tuovinen, \& Sweller, 2001b; Tricot \& Sweller, 2014). Finally, we expect low-achieving students to score higher in mathematical learning under condition 2 (with worked examples supported by domain-specific knowledge), since this condition demonstrates how to apply procedures to specific cases and thus reduces the number of elements that must be processed in working memory (Chen et al., 2016; Eiriksdottir \& Catrambone, 2011; Margulieux \& Catrambone, 2016).

\section{Method}

\section{Context and participants}

The study was conducted in the Netherlands. Participants were drawn from five postsecondary vocational nursing schools and from seven universities of applied sciences, at which a bachelor's nursing programme was offered. Although the educational levels are different for these two groups of students, the mathematical medication training and its content is the same in both educational programmes. The total sample involved 118 students, 10 men and 108 women, aged between 17 and $31(M=19.6, S D=2.4)$. Of this sample, 44 students were following a post-secondary vocational nursing course and 74 were bachelor's nursing students. Students worked on a bring your own device (BYOD) basis in this study, except for two schools in which students used PCs. 
Students had basic computer skills (Mpre $=3.7, S D=0.7 ;$ Min $=1.0$, Max $=5.0)$, but working with a CBVLE was new to them. Each student was compensated with 15 Euros for their contribution and gave active informed consent to take part in the study.

The students were randomly assigned to one of four conditions in the same CBVLE, which provided a structured learning environment based on the instructional design aspects of interleaved practice and feedback: mathematical medication learning without worked examples (condition 1), mathematical medication learning with worked examples involving domain-specific knowledge (condition 2), mathematical medication learning with worked examples involving regular thinking strategies (condition 3), and mathematical medication learning with a combination of both types of worked example (condition 4).

\section{Computer-based virtual learning environment}

The Second Life ${ }^{1}$ platform was used to design a CBVLE to train nursing students in mathematical medication learning (Fig. 1). Students were assigned to avatars and logged into the CBVLE. It was a simulated world in the form of a field hospital comprising 10 tents and was based on a television series from the 1970s called MASH (Mobile Army Surgical Hospital). In this field hospital, there were four medical doctors who each tended to patients in these tents. The name of the patients was matched to the names mentioned in the mathematical medication problems in the CBVLE. The mathematical medication problems were presented in the screen with four answers when students clicked on the patient map (see Fig. 1). Students used the worked examples as a support to solve the mathematical medication problems. After solving the mathematical medication problem, the patient showed that it was the right answer (Thank you nurse, I feel much better) or the wrong answer (Help nurse, I do not feel good). Then, the doctor gave the right answer and the mathematical medication rule. In a tent called 'The Lab', the underlying domain-specific mathematical principles could be practised via two sets of five short exercises. The primary goals of the training were to do the following:

- Help the nursing students learn to recognise the various problem states to which each mathematical theorem applies

- Enhance the mathematical medication competences of the nursing students with a solid base of mathematical facts and procedures

- Motivate nursing students to learn mathematics by integrating a CBVLE with 'real life' situations

- Bridge transfer problems using a CBVLE involving 'real life' situations

\section{Learning materials}

The subject to be learned was the concept of mathematical medication, and specifically the three domains of liquid medication, infusion fluids, and solid medication. We therefore conducted a procedural cognitive analysis with six mathematical subject matter experts (SMEs) to discuss the mathematical concepts, principles and rules, and

${ }^{1}$ Second Life is a free 3D online virtual world where users can create, connect and interact with others across the globe using voice and chat (secondlife.com). 


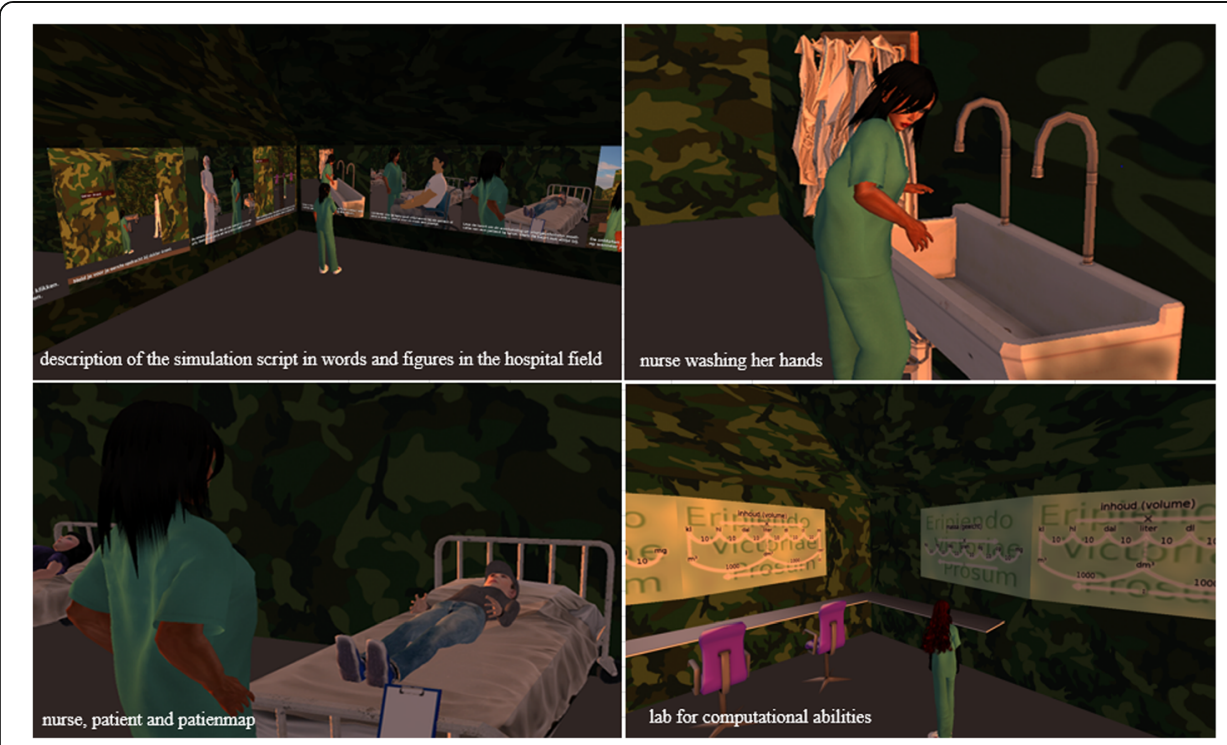

Fig. 1 Screenshots of the MASH learning environment

procedures of five different mathematical medication problems. Each step of the analysis included three questions (Morrison, Ross, Kalman, \& Kemp, 2011, p. 85): (i) What does the learner do? (ii) What does the learner need to know? And (iii) what cues inform the learner that there is a problem, the step is complete, or a different step is needed? For the knowledge audit, the SMEs also discussed and described the contextual knowledge necessary to solve the mathematical medication problem, the reasons why this assignment might be difficult, and the errors students might make. This information was used to create 90 medication scenarios, 100 short exercises on the underlying domain-specific principles, and a worked example involving domain-specific procedural knowledge with an example description, for each domain (Table 1). The student's task was to complete at least one round per training session, consisting six mathematical medication problems and two sets of five short exercises. Each mathematical medication problem formed part of the administration medication process, which was clarified by conducting a task analysis to identify its components and describe them in the form of steps (Morrison et al., 2011). These steps then formed the sequence of actions required in the CBVLE: (i) receive the assignment from a doctor, (ii) wash hands, (iii) communicate with patient, (iv) prepare medication by solving a mathematical medication problem, (v) administer medication, and (vi) update the patient's file and return to the doctor. The doctor may also tell the nurse to go to 'The Lab' to carry out the short exercises.

\section{Procedure}

Mathematical medication teachers from higher and vocational education schools, drawn from the first author's network, were contacted by phone by the first author. When the teachers and their managers had expressed interest in participating in the study and had given consent, they contacted the first author and gave their approval to conduct the study in their schools. The teachers gave fact sheets to the nursing 
students to inform them about the study and its goals, and flyers were also posted on the schools' online platforms with links to allow students to confirm their participation. An initial introduction session was arranged, in which students were informed about the study and filled in consent forms.

Through a pilot study lasting 4 weeks and involving 11 students, we ensured that the learning materials used in the CBVLE were comprehensible, the technical aspects of the CBVLE were functional, and the tests appropriate. As a result of this pilot study, we changed the introduction section to a single shorter meeting, designed a paperbased manual and introduced technical instruction, using photos in the CBVLE to guide students through the practice rounds in the CBVLE (see Fig. 1).

The experimental session consisted of three main phases (see Table 2). During the first of these, an introduction and personal data phase that took 70 min, students were introduced to the CBVLE training via a personal introduction session. In each session, which lasted $30 \mathrm{~min}$, the student was informed about the structure of the upcoming lessons and what was expected from them. Students were then assigned to avatars and logged into the CBVLE. These avatars (students) were randomly allocated one of four conditions. Students practised on one round in the CBVLE, and it was made clear that they were expected to work individually during the game, without help from the researcher or their peers, while paying attention to the information on the screen $(30 \mathrm{~min})$. After this first introduction session, students were asked to complete a questionnaire on their personal data, such as their name, gender, age, and computer skills (10 min).

During the second stage, which was the individual pre-test measurement phase (which lasted a total of $125 \mathrm{~min}$ ), students first received an introductory explanation of how to answer different questions in various surveys on basic computational skills, a non-verbal intelligence test, and domain-specific mathematical knowledge (5 min). Students were then given $15 \mathrm{~min}$ for a test of their basic computational skills, and the standard progressive matrices (SPM) non-verbal intelligence test was applied (Raven, Court, \& Raven, 1992), which took $45 \mathrm{~min}$. After a $10 \mathrm{~min}$ break, students were tested on their domain-specific mathematical knowledge (60 min).

Table 2 Overview of the procedure for the CBVLE study

\begin{tabular}{ll}
\hline Procedure for mathematical medication training in the CBVLE & Duration \\
\hline (1) Introduction and personal data & $70 \mathrm{~min}$ \\
Introductory explanations of the procedure, materials, and the purpose of the research study & $30 \mathrm{~min}$ \\
Students were given avatars, logged in and played a round & $30 \mathrm{~min}$ \\
Personal data questionnaire & $10 \mathrm{~min}$ \\
(2) Individual pre-test measurements & $125 \mathrm{~min}$ \\
Introductory remarks & $5 \mathrm{~min}$ \\
Assessment of computational basic skills & $15 \mathrm{~min}$ \\
Pre-test assessment of domain-specific mathematical knowledge & $60 \mathrm{~min}$ \\
Individual non-verbal intelligence test (RAVEN) & $45 \mathrm{~min}$ \\
(3) Learning phase: CBVLE training & $90 \mathrm{~min} /$ week \\
(4) Post-tests and debriefing & $70 \mathrm{~min}$ \\
Post-test assessment of domain-specific mathematical knowledge & $60 \mathrm{~min}$ \\
Debriefing & $10 \mathrm{~min}$ \\
\hline
\end{tabular}


Week 2 to 5 formed the third stage, which was the learning phase. This phase took 90 min per week ( 45 min per training session), for 4 consecutive weeks. In the fourth stage, involving post-tests and debriefing $(90 \mathrm{~min})$, students were first tested on their domain-specific mathematical knowledge $(60 \mathrm{~min})$ followed by a short debriefing $(10 \mathrm{~min})$. After this, the students' activity logs were uploaded to a disc belonging to the researcher.

\section{Measurements and instruments}

\section{Measurement of nursing students' non-verbal intelligence}

As children get older, the measurement of cognitive abilities requires particular attention to both predisposition factors and acquired skills (Alloway \& Alloway, 2010). This is possible with the SPM test (Raven et al., 1992), which measures students' non-verbal intelligence. The test consists of 60 problems divided into five sets of 12 problems, ranging from easy to complex (A, B, C, D, E). The reliability score for this test in our study was at an average level (Cronbach's $\alpha=.62$ ). The test was given in a paper-based format, and each item consisted of a figure with a missing piece. Below the figure, six or eight possible answers were given to complete the missing piece, only one of which was correct. There was no time limit on the test, but it generally took about $45 \mathrm{~min}$.

\section{Measurement of nursing students' degree of automation of basic computational abilities}

To ascertain the degree of automation of basic computational abilities, a mathematical speed test was completed. This was a validated test in Dutch that measured students' computational skills in terms of addition, subtraction, multiplication, and division (De Vos, 1992). The four types of arithmetic computations were distributed over five columns, with one column for each type of computation and one containing all types in a random order. There were 40 arithmetic assignments per column, and these were presented in ascending order of difficulty. The students had $1 \mathrm{~min}$ per column to solve as many of these arithmetic problems as possible. The more arithmetic assignments a student solved correctly, the higher their score for fundamental computational abilities. Students could obtain scores of between zero and a maximum of 40 per column, and an overall maximum of 200 for the test. The reliability score for this study was high (Cronbach's $\alpha=.90$ ).

\section{Measurement of nursing students' mathematical medication knowledge}

Domain-specific mathematical medication knowledge was assessed with a test composed by Cito (the Dutch national organisation for test development; see Lampe, Straetmans, \& Eggen, 2011), which was used to measure domain-specific mathematical medication knowledge both before and after intervention with the CBVLE. Two parallel versions were therefore developed by Cito. The original domain-specific mathematical medication knowledge test consisted of 50 multiple choice questions, with 20 questions on domain-specific mathematical medication knowledge for infusion fluids, 19 questions on liquid medication, and 11 questions on solid medication (tablets). After an item response analysis, four items with poor discriminatory power were eliminated from the test. Students could obtain a maximum score of 46 for both tests. Cronbach's $\alpha=.80$. The post-test reliability was also good $(\alpha=.83)$. 


\section{Measurement of nursing students' mathematical medication activities in CBVLE}

The students' activities (in the form of solved mathematical medication problems) were logged in the CBVLE, and these logs were used as a control variable for the total numbers of mathematical medication problems solved by nursing students during their sessions. Some computers did not save these logs on students' computers, for safety reasons or due to the amount of space available on disc. We were able to retrieve logs for 60 students, which showed that they completed a mean of 56 activities, a median of 57 , a minimum of 23 , and a maximum of 109.

\section{Data analyses}

A total of 118 students participated in the study. However, due to the spread over eight training sessions and internship commitments, 17 students dropped out of the study (14\%). The results for performance are based on analyses of data from 101 students who completed all the sessions and tests. First, the comparability of the conditions was tested with a one-way analysis of variance (ANOVA). A hierarchical multiple analysis (MRA) was then employed to determine which variables accounted for mathematical medication learning after CBVLE training. A paired sample $t$ test was conducted to find significant differences between mathematical medication results before (pre-test) and after (post-test) the CBVLE training, and more specifically domain-specific knowledge of infusion, fluid medication, and solid medication. A repeated measures ANOVA was used to compare the differences in mathematical medication learning between the conditions. A one-way analysis of covariance (ANCOVA) was also set up to insert the conditions and to indicate whether there were significant differences in nursing students' mathematical medication learning after the CBVLE training, controlling for prior knowledge (pre-test scores), non-verbal intelligence scores (RAVEN), and basic computational abilities. We finished the analysis by combining the non-verbal intelligence scores into three groups of high-achieving, mid-level achieving, and low-achieving students. $\underline{t}$ tests were conducted to calculate the differences in mathematical medication learning. An ANOVA was used to investigate the differences and an ANCOVA to indicate differences to their assigned conditions. The differences between the groups and their conditions were tested using a multivariate analysis of variance (MANOVA).

\section{Ethics}

When students were informed by their teacher about the study, they were given the opportunity to choose to participate in the research. After giving their agreement and after an introductory verbal explanation from the researcher and the teacher of the aims of the CBVLE training research, students could still decline to take part in the research. Students were assured that identifying information was not available to anyone except the researchers. Results were de-identified by numbering both the students and their tests, and files were located in different places under different names. The Faculty Ethics Review Committee (FETC) of the Faculty of Social Sciences of Utrecht University reviewed and approved the research study under case number 19-230. 


\section{Results}

The results for each condition were compared with respect to the basic computational skills, non-verbal intelligence, and prior knowledge of nursing students. No significant differences were found in the degree of automation of basic computational abilities (TTRtot) $(F(3,114)=2.19, p=.09)$, non-verbal intelligence outcomes $(F(3,108)=1.48$, $p=.23$ ), or pre-test scores (prior knowledge) $(F(3,114)=2.35, p=.08)$. More specifically, we found no significant differences in domain-specific knowledge for infusion $(F(3$, $114)=2.59, p=.06)$ or solid medication $(F(3,114)=.83, p=.48)$. However, a significant difference was observed for domain-specific knowledge for liquid medication $(F(3$, $\left.114)=3.62, p<.05, \eta^{2}=.87\right)$. A further Tukey HSD analysis revealed no differences between the four conditions $(p=0.70)$, showing that these conditions are comparable with respect to the basic computational skills, non-verbal intelligence outcomes, and prior knowledge of nursing students. Table 3 gives descriptive statistics for the nursing students' test scores and their performance for each condition in the CBVLE.

\section{Predictors for mathematical medication learning by nursing students in CBVLE training}

To identify which predictors accounted for mathematical medication learning by nursing students after CBVLE training (post-test performance), an MRA was conducted

Table 3 Summary of nursing students' scores for each condition

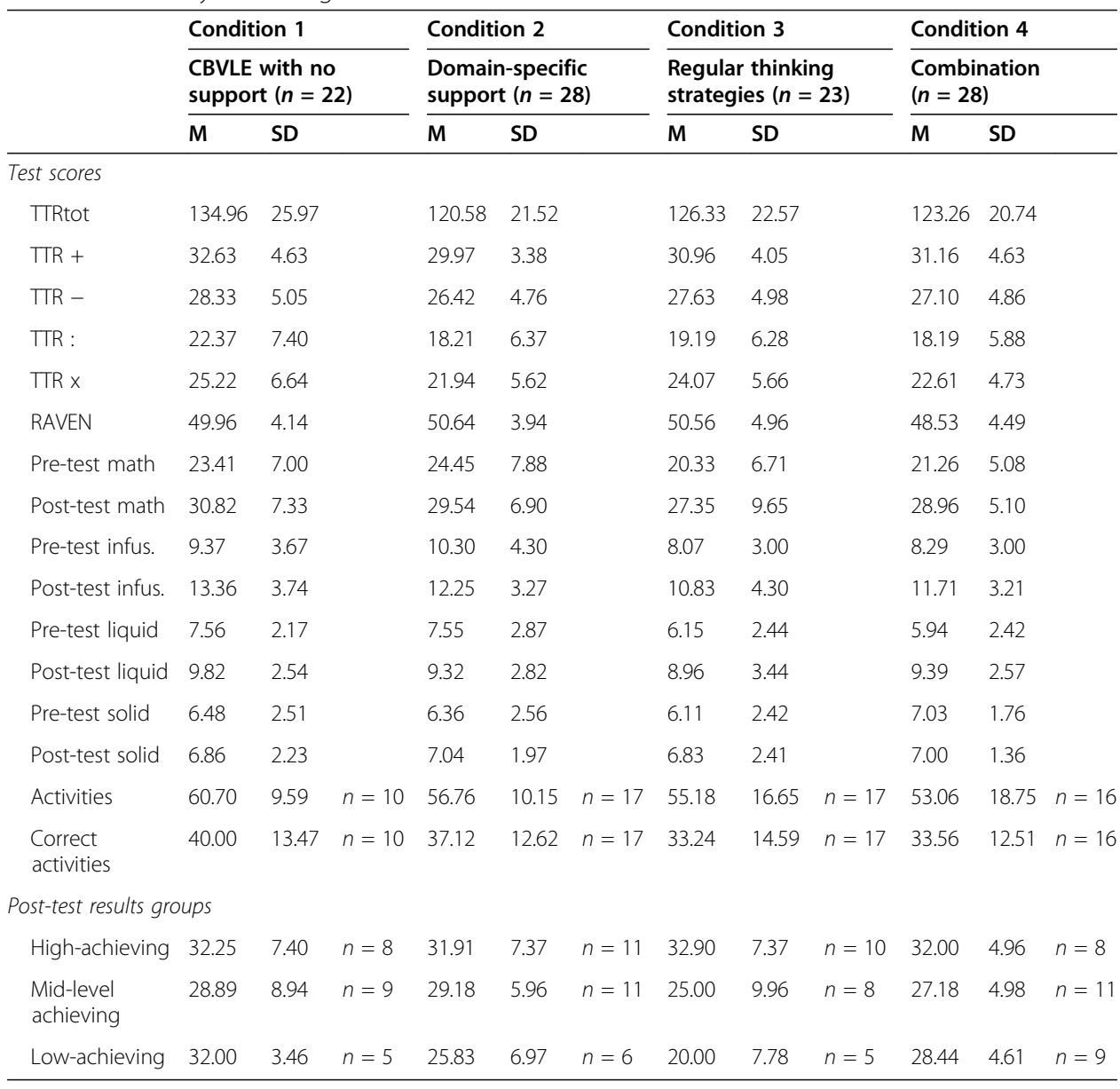


using the number of activities in the CBVLE (based on logs), support (worked examples), basic computational skills (TTRtot), non-verbal intelligence outcomes, and prior knowledge (pre-test performance). Several assumptions were tested, and checks were performed. Stem and leaf plots and boxplots indicated three univariate outliers, which were deleted (two students with exceptionally low scores, and one with an extremely high score). A test to determine whether the data met the assumption of collinearity indicated that multicollinearity was not a concern (support tolerance $=.895$, VIF $=1.12$; pre-test tolerance $=.656, \mathrm{VIF}=1.52$; basic computational skills tolerance $=.762$, VIF $=$ 1.31; non-verbal intelligence tolerance $=.755$, VIF $=1.32$; CBVLE activities tolerance $=$ .839 , VIF $=1.19$; number of correct CBVLE activities tolerance $=.270$, VIF $=3.70$ ). The Mahalanobis distance did not exceed the critical value of $x^{2}$ of 22.46 for $\mathrm{df}=6$ for any cases in the data file, indicating that multivariate outliers were not of concern. In step 1 of the hierarchical MRA, support, prior knowledge, basic computational skills, nonverbal intelligence, and CBVLE activities accounted for $60 \%$ of the variance in mathematical medication learning after training with $\operatorname{CBVLE}\left(R^{2}=.60, F(5,51)=15.42, p=\right.$ $.00)$, a significant proportion. Since the CBVLE activities did not show significant results, the number of correctly solved CBVLE activities was added to the regression equation in step 2, and this accounted for a significant additional $3 \%$ of the variance in compliance $\left(\Delta R^{2}=.03, \Delta F(1,50)=4.45, p<.05\right)$. When combined, the predictor variables explained $63 \%$ of the mathematical medication learning by nursing students after training with CBVLE $\left(R^{2}=.63\right.$, adjusted $\left.R^{2}=.59, F(6,50)=14.46, p=.00\right)$. Table 4 gives unstandardised and standardised regression coefficients and squared semi-partial correlations for each predictor at each step of the hierarchical MRA.

\section{Effects of the CBVLE training}

A paired sample $t$ test across all participants indicated a significant difference between the pre-test and post-test scores $\left(t(100)=10.68, p<.001, \eta^{2}=.89\right)$, in favour of the post-test. More specifically, the domains for infusion $\left(t(100)=8.33, p<.001, \eta^{2}=.76\right)$,

Table 4 Regression coefficients and semi-partial correlations $\left(\mathrm{sr}^{2}\right)$ for each predictor variable

\begin{tabular}{llll}
\hline Variable & $\boldsymbol{B}[\mathbf{9 5 \% ~ C l}]$ & $\boldsymbol{\beta}$ & $\mathbf{s r}^{\mathbf{2}}$ \\
\hline Step 1 & & & \\
Support & $0.90[-0.24,2.04]$ & 0.15 & .02 \\
Prior knowledge & $0.44[0.25,0.64]^{*}$ & 0.49 & .16 \\
Computational skills & $0.03[-0.02,0.09]$ & 0.12 & .01 \\
Non-verbal intelligence & $0.40[0.13,0.67]^{* *}$ & 0.31 & .07 \\
CBVLE activities & $0.66[-0.04,0.67]$ & 0.12 & .01 \\
Step 2 & & & \\
Support & $0.80[-0.31,1.91]$ & 0.13 & .01 \\
Prior knowledge & $0.36[0.15,0.56]$ & 0.40 & .09 \\
Computational skills & $0.03[-0.02,0.08]$ & 0.11 & .01 \\
Non-verbal intelligence & $0.40[0.14,0.66]$ & 0.30 & .07 \\
CBVLE activities & $-0.07[-0.22,0.10]$ & -0.12 & .00 \\
Correct CBVLE activities & $0.18[0.01,0.36]^{* *}$ & 0.35 & .03 \\
\hline
\end{tabular}

$\mathrm{Cl}$ confidence interval ${ }^{*} p<.001,{ }^{* *} p<.05$ 
and liquid medication $\left(t(100)=8.08, p<.001, \eta^{2}=.90\right)$ also showed a significant difference. For solid medication, no significant result was found $(t(100)=1.07, p=.29)$. This shows that all the mathematical medication learning was improved by training with CBVLE. A one-way ANOVA was used to compare the mathematical medication learning outcomes under the four different support conditions in the CBVLE training. No significant differences were found $(F(3,97)=.883, p=.45)$ between the different conditions in terms of the learning outcomes. A covariate was included to partial out the effects of prior knowledge (pre-test). The effect of the support conditions after controlling for prior knowledge was statistically non-significant $(F(3,96)=.678, p=$ .57), and a non-significant result was also found for the support conditions after controlling for basic computational skills $(F(3,93)=.010, p=.99)$. Controlling for nonverbal intelligence scores revealed a significant result $\left(F(3,93)=3.33, p=.02, \eta^{2}=.10\right)$, meaning that after controlling for these scores, the post-test results are significantly related to the support conditions. Post-hoc testing revealed that students with no support from worked examples (condition 1) reported significantly higher learning scores after training with the CBVLE than students with support from regular thinking strategies (condition 3 ) (Mdifference $=5.04, S D=1.98, p=.01$ ). The remaining pairwise comparisons were not significant.

\section{Effects of CBVLE training on high-, mid-level-, and low-achieving students}

Effects of CBVLE training in the high-, mid-level-, and low-achieving groups

The non-verbal intelligence outcomes were divided into three groups $(M=49.9, S D=$ 4.4, Min = 37.0, Max = 59.0) of high-, mid-level-, and low-achieving students. $t$ tests revealed significant differences in low-achieving students' learning, $(t(24)=7.65, p<.00$, $d=1.13)$, mid-level achieving students' learning, $(t(38)=5.58, p<.00, d=0.84)$, and high-achieving students' learning $(t(36)=6.36, p<.00, d=0.94)$. Further analysis found no significant differences between the support conditions in the high-achieving group $(F(3,33)=.041, p=.99)$ and the mid-level achieving group $(F(3,35)=.591, p=.63)$, although in the low-achieving group, significant differences between the support conditions were found $\left(F(3,21)=3.95, p=.02, \eta^{2}=.03\right)$. A Tukey HSD revealed significant differences between students with no support from worked examples (condition 1) and students with support from regular thinking strategies (condition 3$),(M$ diff $=12.0, S D$ $=3.66, p=0.17$ ) (see Fig. 2).

\section{Effects of CBVLE training between the high-, mid-level-, and low-achieving groups}

A significant difference in mathematical medication learning was found between the groups $\left(F(2,98)=5.98, p=.00, \eta^{2}=.11\right)$. A Tukey HSD test showed a difference between the low-achieving and high-achieving group (Mdiff $=-5.43, S D=1.8$ ) and the mid-level achieving and high-achieving group ( $M$ diff $=-4.58, S D=1.6)$. Identifying the differences between the high-achieving, mid-level achieving, and low-achieving nursing students groups based on the support conditions used in the CBVLE, a significant univariate main effect was found for the post-test scores $(F(2,89)=6.37, p=$ $<.00, \eta^{2}=.13$ ), and particularly for the mathematical medication domains of infusion $\left(F(2,89)=5.49, p=.001, \eta^{2}=.11\right)$ and liquid medication $(F(2,89)=6.25, p<$ $\left..00, \eta^{2}=.12\right)$. For solid medication, no univariate main effect was found $(F(2,89)$ 


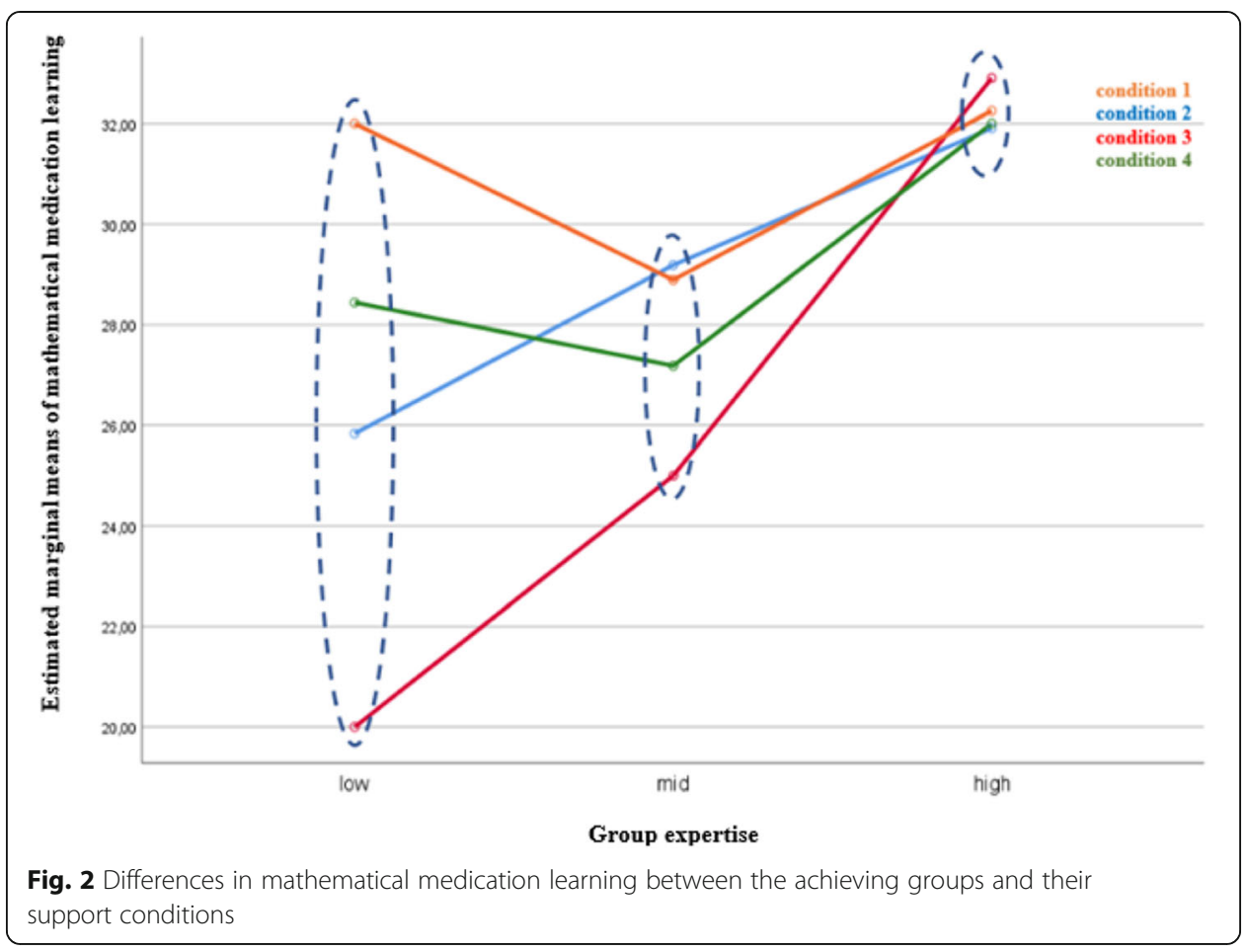

$=1.47, p=.24)$. Further analysis with a Tukey HSD test revealed that these differences related to the groups under condition 1 (with no support from worked examples; $M=13.4, S D=.76$ ) and condition 3 (worked examples with regular thinking strategies; $M=10.3, S D=.75$ ). Figure 2 shows the differences in post-test mathematical medication training for the groups of nursing students (high-achieving/mid-level achieving/low-achieving) and the conditions in which they experienced the CBVLE training (marked with dotted lines).

\section{Discussions}

The overall results of this study confirm our expectations that learning via a CBVLE considering instructional activities as interleaved practice and feedback fosters nursing students' mathematical medication learning. Based on these instructional activities in the CBVLE, nursing students were able to solve different mathematical medication problems within a relatively short time. This corresponds with the findings of Tynjälä (2013), who reports that exposing students to numerous mathematical medication problems trains them in extracting the relevant mathematical information from complex problems. A further detail of Tynjälä's results that is pertinent to this study is that this extraction of information does not relate to the number of exercises but the number of correct exercises in terms of its effect on mathematical medication learning. In addition, nursing students' prior mathematical medication knowledge and their nonverbal intelligence accounted as predictors for mathematical medication learning via the CBVLE. However, when the mathematical learning outcomes were compared under the four different support conditions, controlling for prior knowledge did not reveal any effect between the support conditions and mathematical medication learning outcomes; only controlling for nursing students' non-verbal intelligence accounted for 
significant results. More specifically, when non-verbal intelligence scores were considered, students in condition 1 (without worked examples) scored significantly higher learning outcomes than students in condition 3 (worked examples with the support from regular thinking strategies). This may be attributable to the characteristics of the instructional material of the worked example with regular thinking strategies. To trigger the learner to conduct active thinking, regular thinking strategies should be 'formulated as statements that may be individually and socially negotiated' (Zohar \& David, 2008, p. 60). The worked examples in the CBVLE did not include this linguistic component. Zohar and David (2008) stress the importance of a strong verbal component of thinking strategies. In this CBVLE, thinking strategies were presented only on paper, and this might be the reason that they could not trigger students to carry out active thinking. Moreover, the structure of the learning environment in the CBVLE outlined a domain-specific learning task and had control over many of the information elements and their interactions, which were pre-programmed for the learners. Worked examples may therefore have been redundant. This applied not only to high-achieving students (see Anderson, Fincham, \& Douglas, 1997; Kalyuga, Chandler, \& Sweller, 2001a; Kalyuga, Chandler, Tuovinen, \& Sweller, 2001b; Kirschner et al., 2018; Van Merriënboer \& Sweller, 2010), but also to the low-achieving nursing students. From a cognitive load theory (CLT) perspective, this means that technology has taken over some of the capacity of working memory, which accounts for the benefits to low-achieving learners. Thereby, interleaved practice ensures a broader knowledge base for all nursing students (Dunlosky et al., 2013; Rohrer et al., 2015). Different mathematical medication problems with the same mathematical medication rules distributed in the CBVLE enhance nursing students' retention. Students learn to choose the right strategies next to focus on executing strategies (Rohrer et al., 2014). Students constantly focus on retrieving different solutions, which strengthens memory associations (Rohrer et al., 2015).

Our findings are different from those of Anderson et al. (1997), who state that worked examples can be effective for skill acquisition in well-structured domains such as mathematics. It seems that the amount of information forwarded by the instructional activities in the CBVLE supported nursing students sufficiently in mathematical medication learning. In addition, Gick and Holyoak (1987) state that transfer tasks cue the retrieval of appropriate prior knowledge. In the CBVLE, these transfer tasks took the form of short exercises that encouraged nursing students to retrieve and apply the appropriate underlying knowledge necessary to solve the mathematical medication problems. The similarity of processing may have generated the transfer of knowledge necessary for mathematical medication learning. This is in line with Warner et al. (2020) who state that online instruction should be adapted to students' prior knowledge to improve learning. Another important factor for transfer, according to Gick and Holyoak (1987), is the students' background knowledge of the subject. The CBVLE supports the mathematical medication learning of nursing students in the context of their future professional tasks. This was underlined by the high percentage of nursing students who reported that the CBVLE made them more aware of their skills in medication administration: 90\% (fully) agreed. Consequently, the hypothesis tested in this study that students would benefit from the worked examples supported by domainspecific knowledge (condition 2) was not supported. 
In this study, the mathematical medication learning of low-achieving nursing students improved most. More interesting is the fact that the low-achieving nursing students in condition 1, with no support from worked examples, gained the highest mathematical medication learning results. Worked examples with regular thinking strategies were also detrimental to learning in the low-achievement group. This result is subject to the restrictions on regular thinking strategies mentioned above, but the importance of knowledge should not be underestimated. For some learning tasks, regular thinking strategies may be counterproductive, since knowledge matters (Hirsch Jr., 2016; Tricot \& Sweller, 2014). Sweller (2010) places considerable emphasis on devising techniques that support students' domain-specific knowledge learning, rather than regular skills (Pollock et al., 2002). On the other hand, worked examples with domain-specific knowledge may have imposed an excessive load (see Sweller, 2010), which might be a reason that the hypothesis of the low-achieving students was not supported in this study. The low-achieving students did not show higher mathematical learning outcomes under condition 2 (with worked examples supported by domain-specific knowledge).

The structure of the learning environment in the CBVLE burdens the short-term memory of low-achieving nursing students by focusing on a variety of mathematical medication problems and retrieving different solutions from short-term memory that foster good long-term recall (Roediger \& Karpicke, 2006; Rohrer et al., 2015). This is clearly visible in Fig. 2, where it can be seen that there are big differences in mathematical medication learning in the low-achievement group in terms of the various support conditions in the CBVLE, while the level of support conditions in the CBVLE appears to be unimportant for the experienced students in the high-achieving group. The latter is in line with Mayer (2001) who states that experienced students need less guidance than inexperienced students. Experienced students have more developed schemas that enable to process information automatically and reduce the burden on working memory (Clarke, Ayres, \& Sweller, 2005). This enables students to engage in activities that are more complex. Hence, worked examples are detrimental to the acquisition of skills when levels of expertise are sufficiently high (Kalyuga, Chandler, \& Sweller, 2001a; Kalyuga, Chandler, Tuovinen, \& Sweller, 2001b; Tricot \& Sweller, 2014). Nevertheless, the second hypothesis tested in this study, regarding the expectations that highachieving students were expected to score more highly in mathematical medication learning under condition 1 (no support of worked examples), was not supported. The support conditions in the CBVLE for the high-achieving group appeared to be unimportant for mathematical medication learning.

\section{Conclusions, limitations, and suggestions for future research}

To conclude, we designed the CBVLE with numerous mathematical medication scenarios to create an environment in which nursing students could study the concept of mathematical medication that would be essential in their future profession. Although this study focused on mathematical medication learning, the importance of nursing students' learning in terms of the future task of medication administration should not be underestimated. Our results seem to indicate that the CBVLE can engage nursing students in training on difficult, unclear situations that they are likely to come across in professional practice (Prins et al., 2019). 
This study was an initial attempt to train nursing students in mathematical medication via a CBVLE. This is a form of learning that enables students to engage in transformative and innovative, rather than reproductive, learning (Tynjälä, 2013). Learning can also be facilitated by taking into account the emotional process during learning in the CBVLE (Pekrun, 2011), and it would be interesting to find out whether this is the case in relation to CBVLE training and its effects on learning. We therefore suggest that future research should focus on how the features of a CBVLE can facilitate the emotional process and thus learning, especially for nursing students in mid-level achieving and low-achieving groups. This study used a small sample of participants, especially in the low-, mid-level-, and high-achieving groups, since we were able to only download the activity logs of 60 students. This may limit the generalisability of the findings of the study and may prevent strong claims being made that are not based on coincidence. The findings of this study should therefore be treated cautiously. For instance, although worked examples that can serve the organisation of the knowledge needed to solve complex mathematical medication problems take time to complete, we established a limited time per lesson ( $45 \mathrm{~min}$ ); hence, the nursing students who were given worked examples based on domain-specific procedural knowledge were unable to solve as many mathematical medication problems as the other groups. In future studies, this needs to be considered.

Abbreviations

CBVLE: Computer-based virtual learning environment; CLT: Cognitive load theory

\section{Acknowledgements}

The research reported in this article could not have been possible without the help of Ing. Arjen Breedveld. We would like to express our gratitude for his tremendous support regarding the Second Life platform. Thanks are also due to all the students who participated in this study and their teachers for allowing them to participate.

\section{Authors' contributions}

All authors contributed to the study equally, on the design, data collection, and analysis as well as writing the article. The computer-based virtual learning environment has been programmed by Ing. A. Breedveld. Please note that the authors hold the copyrights of the figures included in this manuscript. All authors read and approved the final manuscript. The manuscript has been officially proofread by PRS.

\section{Funding}

This research was supported by the Netherlands Organization for Scientific Research (NWO) under grant number: 023.006.049.

\section{Availability of data and materials}

Data can be obtained from corresponding author

Competing interests

The authors declare no competing interests.

\section{Author details}

${ }^{1}$ Department of Human Movement and Education, Windesheim University of Applied Sciences, Campus 2-6, 8000, GB, Zwolle, the Netherlands. 'LEARN! Learning Sciences/Teacher Academy, VU Amsterdam, De Boelelaan 1105, 1081, HV, Amsterdam, the Netherlands. ${ }^{3}$ Education and Learning Sciences Chair Group, Wageningen University and Research, PO Box 8130, 6700, EW, Wageningen, the Netherlands. ${ }^{4}$ Faculty of Social and Behavioural Sciences, University of Utrecht, Heidelberglaan 1, 3584, CS, Utrecht, the Netherlands.

Received: 8 October 2020 Accepted: 28 January 2021

Published online: 12 February 2021

\section{References}

Alloway, T. P., \& Alloway, R. G. (2010). Investigating the predictive roles of working memory and IQ in academic attainment. Journal of Experimental Child Psychology, 106, 20-29. https://doi.org/10.1016/j.jecp.2009.11.003.

Anderson, J. R., Fincham, J. M., \& Douglas, S. (1997). The role of examples and rules in the acquisition of a cognitive skill. Journal of Experimental Psychology, 23, 932-945.

Ausubel, D. P. (1968). Educational psychology: A cognitive view. New York: Holt, Rinehart and Winston. 
Ben-David, A., \& Zohar, A. (2009). Contribution of meta-strategic knowledge to scientific inquiry learning. International Journal of Science Education, 31, 1657-1682. https://doi.org/10.1080/09500690802162762.

Boyle, E., Hainey, T., Connolly, M., Gray, G., Earp, J., Ott, M., ... Riberio, C. (2016). An update to the systematic literature review of empirical evidence of the impacts and outcomes of computer games and serious games. Computers in Education, 94, 178-192. https://doi.org/10.1016/j.compedu.2015.11.003.

Canobi, K. H. (2009). Concept-procedure interactions in children's addition and subtraction. Journal of Experimental Child Psychology, 102, 131-149. https://doi.org/10.1016/j.jecp.2008.07.008.

Chen, O., Kalyuaga, S., \& Sweller, J. (2016). Relations between the worked example and generation effects on immediate and delayed tests. Learning and Instruction, 45, 20-30. https://doi.org/10.1016/.learninstruc.2016.06.007.

Clarke, T., Ayres, P., \& Sweller, J. (2005). The impact of sequencing and prior knowledge on learning mathematics through spreadsheet applications. Educational Technology Research and Development, 53, 15-24. https:/doi.org/10.1007/BF02504794.

Csikszentmihalyi, M. (1990). Flow: The psychology of optimal experience. New York: Harper Collins Publishers.

De Vos, T. (1992). Tempo Toets Rekenen [tempo test mathematics]. Nijmegen: Berkhout.

Dunlosky, J. (2013). Strengthening the student toolbox. Student strategies to boost learning American Educator, Fall 2013. Retrieved from https://www.aft.org/sites/default/files/periodicals/dunlosky.pdf.

Dunlosky, J., Rawson, K. A., Marsh, E. J., Nathan, M. J., \& Willingham, D. T. (2013). Improving students' learning with effective learning techniques: Promising directions from cognitive and educational psychology. Psychological Science in the Public Interest, 14, 4-58.

Eiriksdottir, E., \& Catrambone, R. (2011). Procedural instructions, principles, and examples: How to structure instructions for procedural tasks to enhance performance, learning, and transfer. Human Factors, 53, 749-770. https://doi.org/10.1177/001 8720811419154.

Gick, M. L., \& Holyoak, K. J. (1987). The cognitive basis of knowledge transfer. In S. M. Cormier, \& J. D. Hagman (Eds.), Transfer of learning: Contemporary research and applications, (pp. 9-46). San Diego: Academic Press.

Hattie, J., \& Gan, M. J. (2011). Instruction based on feedback. In R. E. Mayer, \& P. A. Alexander (Eds.), Handbook of research on learning and instruction, (pp. 249-271). New York: Routledge.

Hattie, J., \& Timperly, H. (2007). The power of feedback. Review of Educational Research, 77, 81-112. https://doi.org/10.3102/ 003465430298487

Hirsch Jr., E. D. (2016). Why knowledge matters. Rescuing our children from failed educational theories. Cambridge: Harvard Education Press.

Kalyuga, S., Chandler, P., \& Sweller, J. (2001a). Learner experience and efficiency of instructional guidance. Educational Psychology, 21, 5-23. https://doi.org/10.1080/01443410124681.

Kalyuga, S., Chandler, P., Tuovinen, J., \& Sweller, J. (2001b). When problem solving is superior to studying worked examples. Journal of Educational Psychology, 93, 579-588. https://doi.org/10.1037/0022-0663.93.3.579.

Kirschner, P. A., Sweller, J., \& Clark, R. E. (2006). Why minimal guidance during instruction does not work: An analysis of the failure of constructivist, discovery, problem-based, experiential, and inquiry-based teaching. Educational Psychologist, 41, 75-86. https://doi.org/10.1207/s15326985ep4102_1.

Kirschner, P. A., Sweller, J., Kirschner, F., \& Zambrano, R. J. (2018). From cognitive load theory to collaborative load theory. International Journal of Computer-Supported Collaborative Learning, 13, 213-233. https://doi.org/10.1007/s11412-018-9277-y.

Krathwohl, D. R. (2002). A revision of Bloom's taxonomy: An overview. Theory Into Practice, 41, 212-218,

Lampe, T., Straetmans, G., \& Eggen, T. (2011). De rekenvaardigheid van de Nederlandse verpleegkundige [nurses' mathematical skills in the Netherlands]. Onderwijs en Gezondheidszorg, 35(3), 3-9. https://doi.org/10.1007/s12477011-0030-y.

Lee, E. A.-L., \& Wong, K. W. (2014). Learning with desktop virtual reality: Low spatial ability learners are more positively affected. Computers in Education, 79, 49-58. https://doi.org/10.1016/j.compedu.2014.07.010.

Lee, E. A.-L., Wong, K. W., \& Fung, C. C. (2010). How does desktop virtual reality enhance learning outcomes? A structural equation modeling approach. Computers \& Education, 55, 1424-1442. https://doi.org/10.1016/j.compedu.2 010.06.006.

Margulieux, L., \& Catrambone, R. (2016). Improving problem solving with subgoal labels in expository text and worked examples. Learning and Instruction, 42, 58-71. https://doi.org/10.1016/j.learninstruc.2015.12.002.

Mayer, R. M. (2001). Multimedia learning. New York: Cambridge University Press.

Morrison, G. R., Ross, S. M., Kalman, H. K., \& Kemp, J. E. (2011). Designing effective instruction. Hoboken: Wiley.

Nicol, D. J., \& Macfarlane-Dick, D. (2006). Formative assessment and self-regulated learning: A model and seven principles of good feedback practice. Studies in Higher Education, 31, 199-218. https://doi.org/10.1080/03075070600572090.

Noroozi, O., Biemans, H. J. A., Weinberger, A., Mulder, M., \& Chizari, M. (2013). Scripting for construction of a transactive memory system in multidisciplinary CSCL environments. Learning and Instruction, 25, 1-12. https://doi.org/10.1016/j.lea minstruc.2012.10.002.

Pekrun, R. (2011). Emotions as drivers of learning and cognitive development. In R. A. Calvo, \& S. K. D'Mello (Eds.), New perspectives on affect and learning technologies, Exploration in the learning sciences, instructional systems and performance technologies (vol. 3, pp. 23-39). New York: Springer.

Pollock, E., Chandler, P., \& Sweller, J. (2002). Assimilating complex information. Learning and Instruction, 12, 61-86. https://doi. org/10.1016/50959-4752(01)00016-0.

Polya, G. (1973). How to solve it: A new aspect of mathematical method. Princeton: Princeton University Press.

Prins, H., Zwart, D. P., Voogt, J., \& Hettinga, M. (2019). Which professional contexts can enrich the training of medication skills of nurses through virtual reality? Retrieved from http://healthbytech.com/wp-content/uploads/Abstract-bookSupportingHealth-5.pdf.

Raven, J. C., Court, J. H., \& Raven, J. (1992). Standard progressive matrices (SPM). (1992nd). Oxford: Oxford Psychologists Press.

Rittle-Johnson, B., Siegler, R. S., \& Alibali, M. W. (2001). Developing conceptual understanding and procedural skill in mathematics: An iterative process. Journal of Educational Psychology, 93, 346-362. https://doi.org/10.1037/0022-0663. 93.2.346.

Roediger, H. L., \& Karpicke, J. D. (2006). The power of testing memory: Basic research and implications for educational practice. Perspectives on Psychological Science, 1, 181-210. 
Rohrer, D., Dedrick, R. F., \& Burgress, K. (2014). The benefit of interleaved mathematics practice is not limited to superficially similar kinds of problems. Psychonomic Bulletin \& Review, 21, 1323-1330. https://doi.org/10.3758/s13423-014-0588-3.

Rohrer, D., Dedrick, R. F., \& Stershic, S. (2015). Interleaved practice improves mathematics learning. Journal of Educational Psychology, 107, 900-908. https://doi.org/10.1037/edu0000001.

Sadler, D. R. (2010). Beyond feedback: Developing student capability in complex appraisal. Assessment \& Evaluation in Higher Education, 35, 535-550. https://doi.org/10.1080/02602930903541015.

Schön, D. A. (1983). The reflective practitioner. London: Basic Books.

Shute, V., Ventura, M., Bauer, M., \& Zapata-Rivera, D. (2009). Melding the power of serious games and embedded assessment to monitor and foster learning. In U. Ritterfeld, M. Cody, \& P. Vorderer (Eds.), Serious games: Mechanisms and effects, (pp. 295-321). New York: Routledge.

Sweller, J. (2010). Element interactivity and intrinsic, extraneous, and germane cognitive load. Educational Psychology Review, 22, 123-138. https://doi.org/10.1007/s10648-010-91285.

Tricot, A., \& Sweller, J. (2014). Domain-specific knowledge and why teaching generic skills does not work. Educational Psychology Review, 26, 265-283. https://doi.org/10.1007/s10648013-9243-1.

Tynjälä, P. (2013). Toward a 3-P model of workplace learning: A literature review. Vocations and Learning, 6, 11-36. https://doi. org/10.1007/s12186-012-9091-z.

Van Gog, T., Kester, L., \& Paas, F. (2011). Effects of worked examples, example-problem, and problem-example pairs on novices' learning. Contemporary Educational Psychology, 36, 212-218. https://doi.org/10.1016/j.cedpsych.2010.10.004

Van Merriënboer, J. J., \& Sweller, J. (2010). Cognitive load theory in health professional education: Design principles and strategies. Medical Education, 44, 85-93. https://doi.org/10.1111/j.1365-2923.2009.03498.x.

Wang, M., Kirschner, P. A., Spector, J. M., \& Ge, X. (2018). Computer-based learning environments for deeper learning in problem-solving contexts. Computers in Human Behavior, 87, 403-405. https://doi.org/10.1016/j.chb.2018.06.026.

Warner, D. O., Nolan, M., Garcia-Marcinkiewicz, A., Schultz, C., Warner, M. A., Schroeder, R., \& Cook, D. A. (2020). Adaptive instruction and learner interactivity in online learning: A randomized trial. Advances in Health Sciences Education, 25, 95109. https://doi.org/10.1007/s10459-019-09907-3.

Weeks, K. W., Hutton, B. M., Young, S., Coben, D., Clochesy, J. M., \& Pontin, D. (2013). Competency modelling and diagnostic error assessment in medication dosage calculation problem-solving. Nurse Education in Practice, 13, 23-32. https://doi. org/10.1016/j.nepr.2012.10.013.

Xinhao, X., \& Fengfeng, K. (2016). Designing a virtual reality based, gamelike math learning environment. American Journal of Distance Education, 30, 27-38. https://doi.org/10.1080/08923647.2016.1119621.

Zohar, A., \& David, A. B. (2008). Explicit teaching of meta-strategic knowledge in authentic classroom situations. Metacognition and Learning, 3, 59-82. https://doi.org/10.1007/s11409-007-9019-4.

\section{Publisher's Note}

Springer Nature remains neutral with regard to jurisdictional claims in published maps and institutional affiliations.

\section{Submit your manuscript to a SpringerOpen ${ }^{\circ}$ journal and benefit from:}

- Convenient online submission

- Rigorous peer review

- Open access: articles freely available online

High visibility within the field

- Retaining the copyright to your article

Submit your next manuscript at $\boldsymbol{s p r i n g e r o p e n . c o m ~}$ 